\title{
Exacerbation of Bloody Diarrhea as a Side Effect of Mesalamine Treatment of Active Ulcerative Colitis
}

\author{
Yuichi Shimodate $^{\mathrm{a}}$ Kunihiro Takanashi ${ }^{\mathrm{a}}$ Eriko Waga ${ }^{\mathrm{a}}$ \\ Tomoki Fujita $^{\mathrm{a}}$ Shinichi Katsuki ${ }^{\mathrm{a}}$ Masafumi Nomura ${ }^{\mathrm{b}}$ \\ a Department of Gastroenterology, Otaru Ekisaikai Hospital, Otaru, and ${ }^{\mathrm{b} C e n t e r ~ f o r ~}$ \\ Gastroenterology, Teine Keijinkai Hospital, Sapporo, Japan
}

\section{Key Words}

Mesalamine · Diarrhea $\cdot$ Side effect $\cdot$ Drug lymphocyte stimulation test $\cdot$ Rechallenge trial

\begin{abstract}
Mesalamine has been used as the first-line therapy for the treatment of ulcerative colitis (UC) because of its efficacy and fewer side effects. However, earlier study showed that mesalamine occasionally causes diarrhea. We are presenting a patient with active UC in whom bloody diarrhea accompanied by abdominal pain and fever occurred and the symptoms were aggravated after administration of mesalamine. In order to clarify the reason of symptoms aggravation, drug lymphocyte stimulation test and rechallenge trial with mesalamine were performed. The results indicated the possibility that aggravation was related to allergic reaction and was dose-dependent. Furthermore, we examined colonoscopic views but there was no remarkable change in before and after rechallenge trial. Based on the above result, the patient was diagnosed with mesalamine intolerance. In order to differentiate whether the exacerbation of bloody diarrhea is due to the side effects of the mesalamine or a true relapse of UC, taking careful history before and after increasing mesalamine dosage as well as being aware of side effects of mesalamine are required. Clinicians should be aware of diarrhea as a side effect of mesalamine particularly after onset of mesalamine formulation, change in mesalamine formulation, or change in mesalamine dose.
\end{abstract}

\section{Introduction}

Sulfasalazine has been the first-line therapy for mild to moderately active ulcerative colitis (UC) and also for maintenance of remission in UC since earlier studies $[1,2]$ demonstrated its efficacy. Sulfasalazine is a pro-drug comprising mesalamine 


\begin{tabular}{c|l|l|l}
$\begin{array}{r}\text { Case Reports in } \\
\text { Gastroenterology }\end{array}$ & $\begin{array}{l}\text { Case Rep Gastroenterol 2011;5:159-165 } \\
\text { DOI: 10.1159/000326931 }\end{array}$ & $\begin{array}{l}\text { Published online: } \\
\text { April 12, 2011 }\end{array}$ & $\begin{array}{l}\text { O 2011 S. Karger AG, Basel } \\
\text { ISSN 1662-0631 } \\
\text { www.karger.com/crg }\end{array}$ \\
\hline
\end{tabular}

(5-aminosalicylic acid, 5-ASA) and sulfapyridine joined by an azo band. Azad Khan et al. [3] reported mesalamine to reduce the inflammation of UC. Azo band linkage in sulfasalazine enables mesalamine to reach the inflamed area of UC, where bacterial enzymes split the azo band [4]. There is a dose-dependent adverse event that limits acute and chronic use of sulfasalazine. The sulfapyridine moiety of sulfasalazine is considered to be attributed to most cases of mesalamine intolerance [5]. To eliminate the toxicity associated with sulfasalazine and to prevent mesalamine absorption in the proximal small bowel [6], various mesalamine formulations have been developed. Two different mesalamine formulations, $\mathrm{pH}$-dependent release $\left(\mathrm{Asacol}^{\circledR}\right)$ and time-dependent release $\left(\right.$ Pentasa ${ }^{\circledR}$ ) are now available in Japan. Since some controlled studies [7-10] demonstrated the efficacy and safety of mesalamine formulations, mesalamine is currently the most commonly used drug in the treatment of active and quiescent UC. Although mesalamine is recognized as a well-tolerated drug, some adverse events have also been reported. While allergic and nephrotoxic reactions and acute pancreatitis induced by mesalamine are well recognized $[11,12]$, diarrhea as a side effect of mesalamine treatment is rare. Here we present a case of mesalamine-induced exacerbation of bloody diarrhea in a patient with active UC.

\section{Case Report}

A 14-year-old male presenting with bloody diarrhea of 1 month duration was referred to our hospital. He was diagnosed with UC of left-sided colitis by total colonoscopy and histology. He started to receive $\mathrm{pH}$-dependent release mesalamine (Asacol) at 3,600 mg/day, which seemed to aggravate bloody diarrhea and to induce abdominal pain and fever. Then Asacol was switched to time-dependent release mesalamine (Pentasa) at 4,000 $\mathrm{mg} /$ day, but the symptoms did not improve. Physical examination revealed high temperature $\left(37.8^{\circ} \mathrm{C}\right)$ and mild tenderness without rebound tenderness in the lower quadrant abdomen.

Laboratory examinations on admission showed that CRP was slightly elevated $(1.16 \mathrm{mg} / \mathrm{dl})$ and that peripheral eosinophils were normal. Cytomegalovirus antigenemia study and cytomegalovirus in histological results of colorectal biopsy specimen were negative. Colonoscopy on admission revealed disappearance of the vascular pattern and diffuse granular mucosa and erosion that was noted continuously from the rectum to the decending colon (fig. 1). The patient was submitted to drug lymphocyte stimulation test (DLST) against Asacol and Pentasa because based on his clinical course, we assumed that the symptoms were related to side effects of mesalamine rather than true exacerbation of UC. Fever, bloody diarrhea and abdominal pain completely disappeared and CRP normalized as soon as he discontinued mesalamine with methylpredonisolone $500 \mathrm{mg}$ pulse therapy. Furthermore, he was started on intensive treatment of granulocyte and monocyte adsorptive apheresis (GCAP). DLST against Asacol and Pentasa resulted in 1,635 and 2,232\%, both result being strongly positive (a value of more than $200 \%$ is defined as positive reaction). A rechallenge trial with mesalamine was performed to confirm the nature of his mesalamine intolerance objectively. After informed consent, he was administered $400 \mathrm{mg} /$ day of Asacol the dose was increased up to 2,400 $\mathrm{mg}$ (fig. 2 ). Bloody diarrhea, abdominal pain and fever were noted at 1,600 mg/day, and Asacol was discontinued at 2,400 mg/day. These symptoms disappeared only few days after of Asacol withdrawal (fig. 3 ). Regardless of apparently exacerbated clinical symptoms, there was no remarkable change in colonoscopic view at 2,400 mg/day compared to that prior to the rechallenge trial (fig. 4). Therefore, he was diagnosed to be mesalamine-intolerant and treated with predonisolone sodium phosphate enema (Predonema $\left.{ }^{\circledR}\right)$. 


\begin{tabular}{c|l|l|l}
$\begin{array}{r}\text { Case Reports in } \\
\text { Gastroenterology }\end{array}$ & $\begin{array}{l}\text { Case Rep Gastroenterol 2011;5:159-165 } \\
\text { DOI: 10.1159/000326931 }\end{array}$ & $\begin{array}{l}\text { Published online: } \\
\text { April 12, 2011 }\end{array}$ & $\begin{array}{l}\text { O 2011 S. Karger AG, Basel } \\
\text { ISSN 1662-0631 } \\
\text { www.karger.com/crg }\end{array}$ \\
\hline
\end{tabular}

\section{Discussion}

This report documents the importance of recognizing mesalamine-related side effects whose symptoms are similar to those of UC relapse. Mesalamine formulations have replaced sulfasalazine as the first-choice treatment of UC due to their less frequent causation of sulfa-related adverse events. However, several previous studies have reported mesalanine-related side effects, including severe allergic reaction. Marteau et al. [11] documented the incidence of Pentasa-related adverse events for 2 years (from 1 January 1993 to 31 December 1994) in France, which was 6.6 and 9.0 per million days of therapy in 1993 and 1994. As far as adverse events of digestive disorders go, five cases of diarrhea attributed to 5-ASA were reported, which was estimated to be 0.36 per million days of therapy with Pentasa. In previous studies $[9,10]$, diarrhea as a treatment-related adverse event is recorded in $1.0-4.6 \%$ of patients, whereas abdominal pain and fever are recorded in about $1-5$ and $1.5 \%$ of patients, respectively. While allergic and nephrotoxic side effects of mesalamine are well recognized, diarrhea as a side effect of mesalamine as well as mesalamine-induced abdominal pain and fever is less recognized among most clinicians.

Interestingly, the results of DLST and the rechallenge trial in our case indicated that not only diarrhea as a side effect of mesalamine, but also allergic reactions were dose-dependent. DLST is utilized to confirm the sensitivity to a specific drug. However, DLST merely serves as an adjunct in the diagnosis of drug-induced allergic reaction because sensitivity and specificity of DLST against mesalamine are not clear. However, the strongly positive result of DLST in our case made us assume that the symptoms were associated with allergic reaction. Yet a few previous studies reported that the mechanism of mesalamine-induced diarrhea was dose-dependent. Scheurlen et al. [13] mentioned that the mechanism of diarrhea caused by mesalamine formulations was thought to be a concentration-dependent inhibition of ileal and colonic $\mathrm{Na}^{+} \mathrm{K}^{+}$ATPase which leads to reduce absorption and increased secretion of water, thus increasing the fluid load to the colon. Goldstein et al. [14] also reported five cases of inflammatory bowel disease including two cases of UC, two of Crohn disease and one of indeterminate colitis, with diarrhea as a side effect of mesalamine treatment. They assumed that diarrhea induced by mesalamine was not allergic but dose-dependent by the fact that diarrhea was easily controlled by reducing the dose of mesalamine in two of five cases. Furthermore, this type of diarrhea is usually watery and blood-tinged rather than grossly bloody. Indeed, in our case, watery and blood-tinged diarrhea gradually developed as the dose of mesalamine in the rechallenge trial increased. This result raises the possibility of a dose-dependent mechanism and tolerance to a moderate dose of mesalamine as induction and maintenance therapy.

Rechallenge trial is the most accurate method to verify the relationship between a specific drug and a side effect. Marteau et al. [11] reported rechallenge trials with Pentasa or other 5-ASA-containing drugs (olsalazine or sulfasalazine) after adverse events in 14 patients including one case of diarrhea, and all rechallenge trials were positive. Mesalamine is a key drug for treatment of UC, therefore it is sometimes necessary to consider a rechallenge trial for diagnosis of mesalamine intolerance. Since a rechallenge trial can provoke life-threatening reactions, providing informed consent is absolutely required.

In terms of the influence of a rechallenge trial with mesalamine on endoscopic changes, Kapur et al. [15] assessed the sigmoidoscopic changes after rechallenge trial with 


\begin{tabular}{c|l|l|l}
$\begin{array}{r}\text { Case Reports in } \\
\text { Gastroenterology }\end{array}$ & $\begin{array}{l}\text { Case Rep Gastroenterol 2011;5:159-165 } \\
\text { DOI: 10.1159/000326931 }\end{array}$ & $\begin{array}{l}\text { Published online: } \\
\text { April 12, 2011 }\end{array}$ & $\begin{array}{l}\text { O 2011 S. Karger AG, Basel } \\
\text { ISSN 1662-0631 } \\
\text { www.karger.com/crg }\end{array}$ \\
\hline
\end{tabular}

mesalamine in clinically and endoscopically quiescent UC. Sigmoidoscopy after the rechallenge trial showed markedly inflamed mucosa up to the descending colon as well as exacerbation of clinical symptoms. However, no remarkable change was observed in sigmoidoscopic inflammation of our case before and after the rechallenge trial, which did not corresponded with previous reports. Further studies are required to show whether mesalamine-induced diarrhea influences endoscopic findings.

In conclusion, clinicians should be aware of diarrhea as a side effect of mesalamine, particularly after onset of mesalamine formulation, change in mesalamine formulation, or change in mesalamine dose. Further clinical and experimental studies are required to clarify the mechanism of diarrhea as a side effect of mesalamine formulations and to differentiate mesalamine-induced diarrhea from true UC relapse.

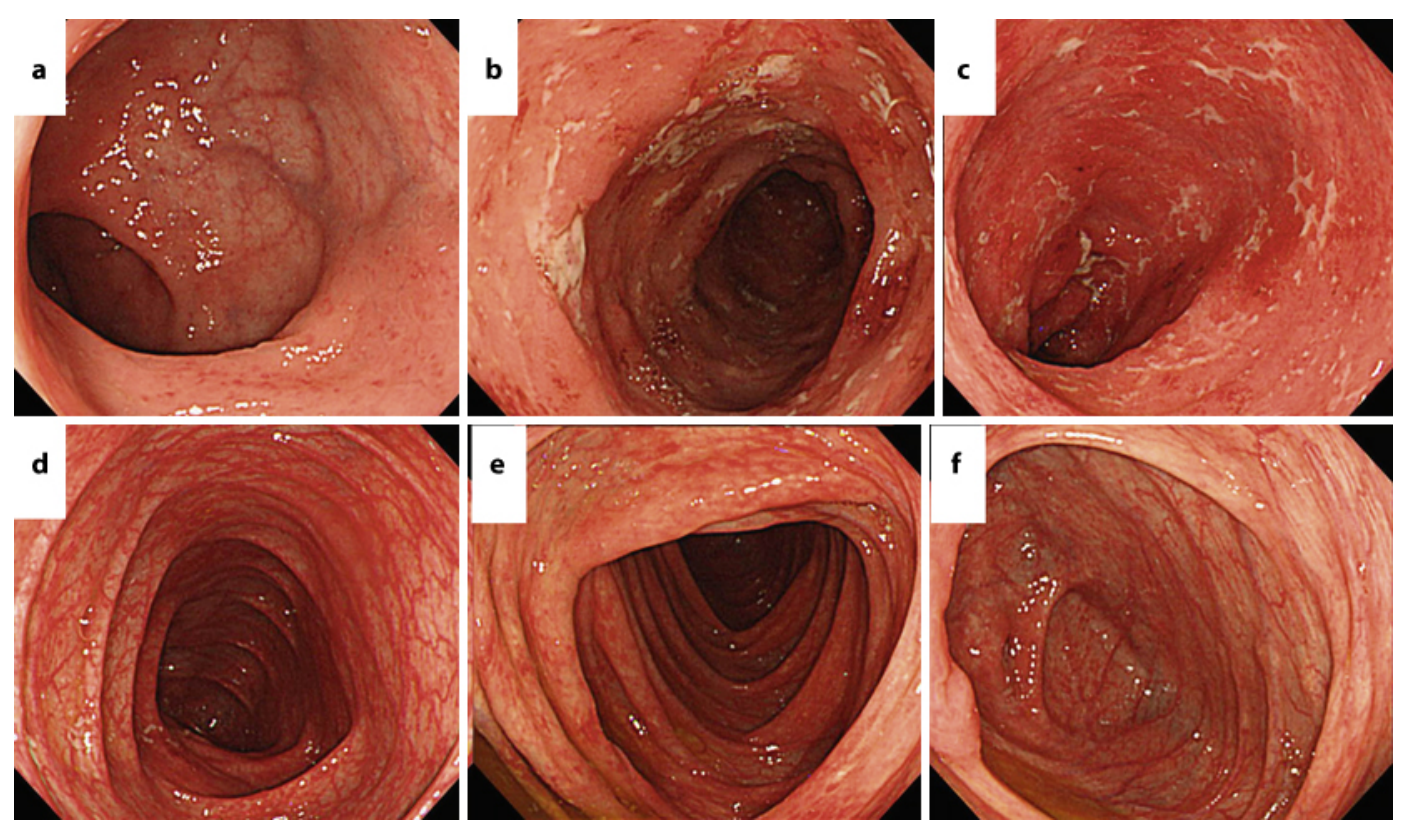

Fig. 1. Colonoscopy on admission revealed disappearance of the vascular pattern and diffuse granular mucosa that was continuously noted from the rectum to the descending colon. a Rectum. b Sigmoid colon. c Decending colon. d Transverse colon. e Ascending colon. f Cecum. 


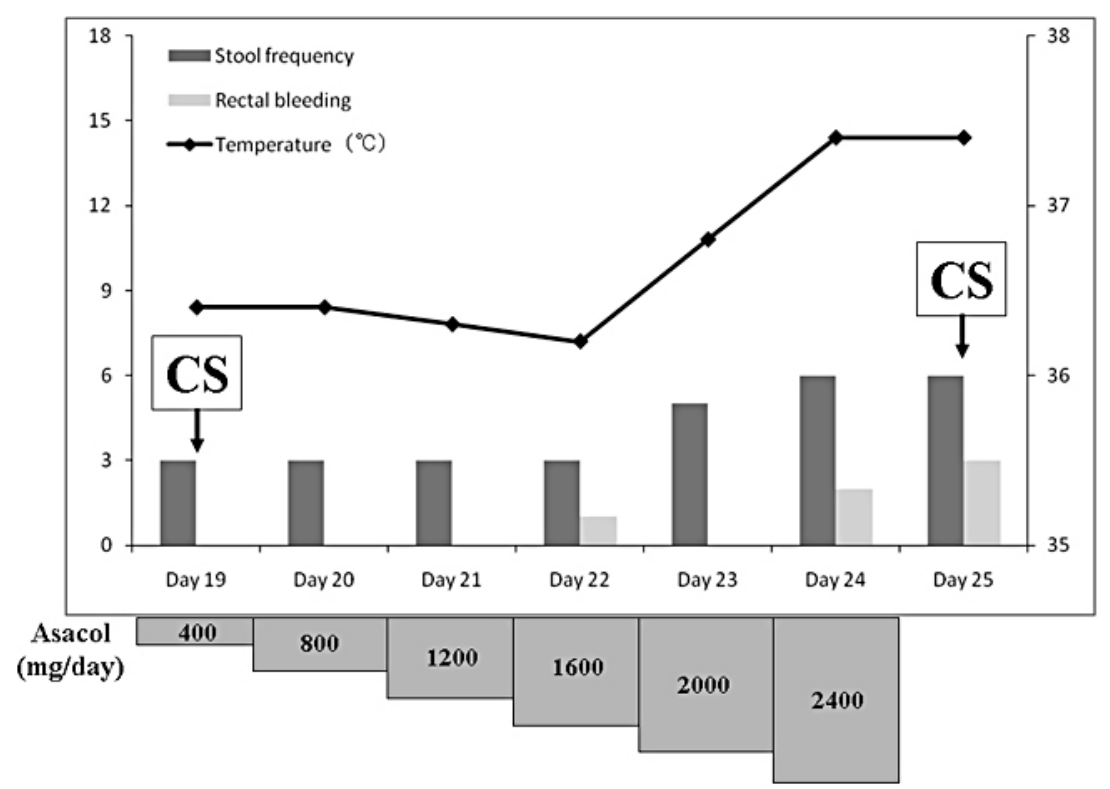

Fig. 2. Rechallenge trial with Asacol. A dose of $400 \mathrm{mg} /$ day of Asacol was administered and increased up to $2,400 \mathrm{mg} /$ day. Bloody diarrhea, abdominal pain and fever were observed at a dose of 1,600 mg/day, then Asacol was discontinued at 2,400 mg/day.

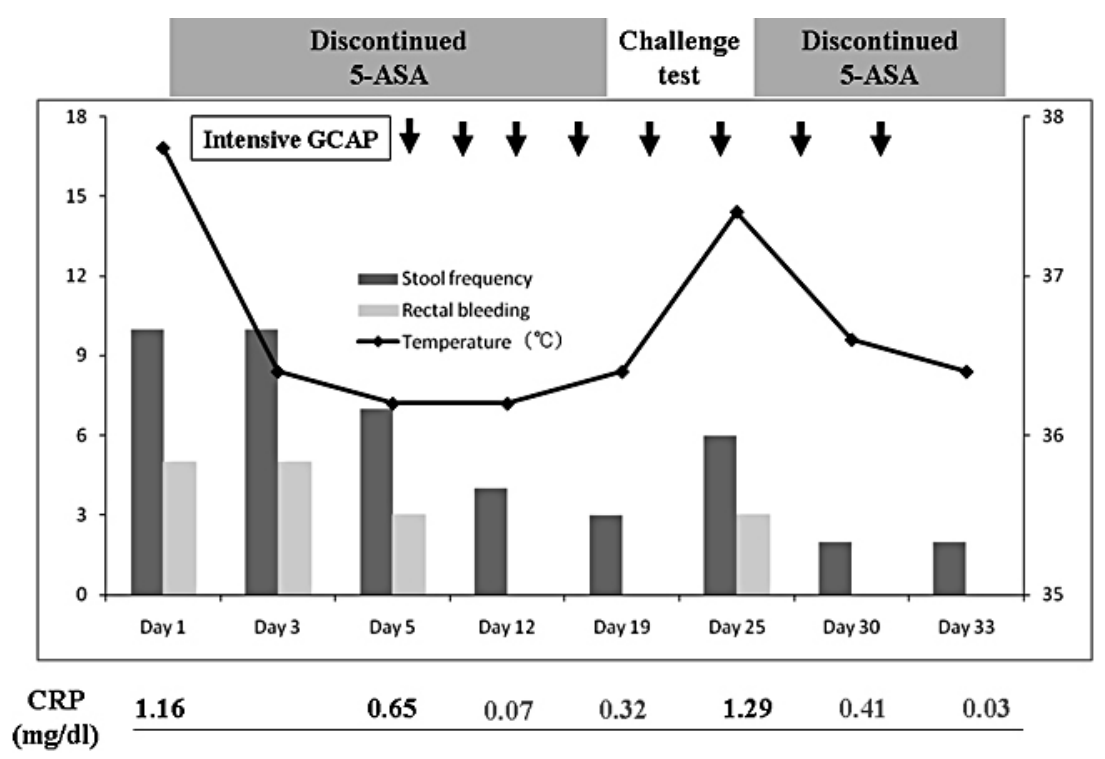

Fig. 3. Clinical course in our case. Stool frequency, rectal bleeding and fever were reduced with withdrawal of mesalamine. 


\begin{tabular}{c|l|l|l}
$\begin{array}{r}\text { Case Reports in } \\
\text { Gastroenterology }\end{array}$ & $\begin{array}{l}\text { Case Rep Gastroenterol 2011;5:159-165 } \\
\text { DOl: 10.1159/000326931 }\end{array}$ & $\begin{array}{l}\text { Published online: } \\
\text { April 12, 2011 }\end{array}$ & $\begin{array}{l}\text { @ 2011 S. Karger AG, Basel } \\
\text { ISSN 1662-0631 } \\
\text { www.karger.com/crg }\end{array}$ \\
\hline
\end{tabular}
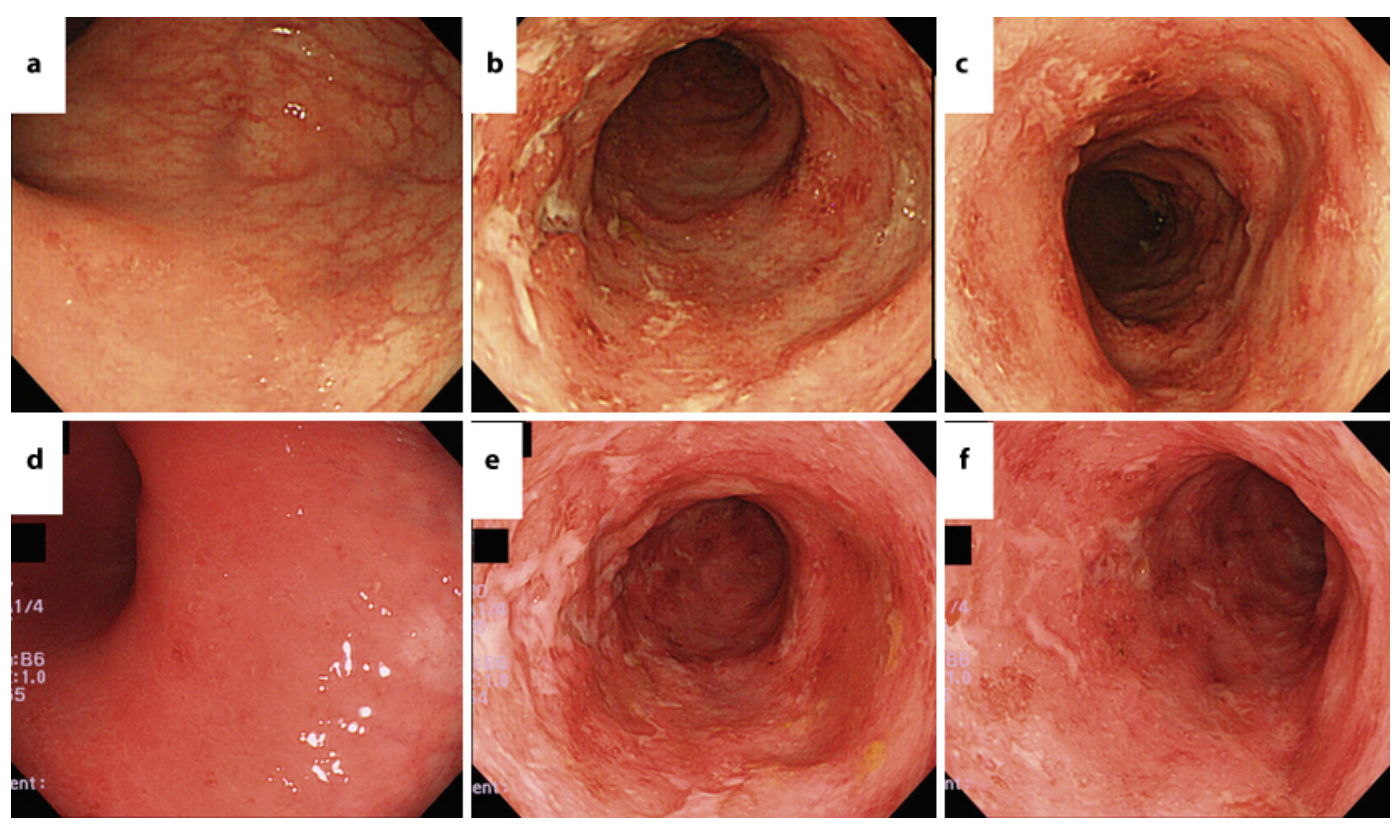

Fig. 4. Colonoscopic findings on day 19 and day 25. Colonoscopy on day 25 revealed no remarkable change compared to prior to administration (on day 19) of Asacol. a, d Rectum. b, e Sigmoid colon. c, f Descending colon. a-c Colonoscopic findings on day 19. c-f Colonoscopic findings on day 25.

\section{References}

1 Dick AP, Grayson MJ, Carpenter RG, et al: Controlled trial of sulfasalazine in the treatment of ulcerative colitis. Gut 1964;5:437-442.

2 Dissanayake AS, Truelove SC: A controlled therapeutic trial of long-term maintenance treatment of ulcerative colitis with sulafasalazine (Salazopyrin). Gut 1973;14:923-926.

-3 Azad Khan AK, Piris J, Truelove SC, et al: An experiment to determine the active therapeutic moiety of sulfasalazine. Lancet 1977;2:892-895.

4 Peppercorn MA, Goldman P: The role of intestinal bacteria in the metabolism of salicylazosulfapyridine. J Pharmacol Exp Ther 1972;181:555-562.

5 Das KM, Eastwood MA, McManus JP, et al: Adverse reactions during salicylazosulfapyridine therapy and the relation with drug metabolism and acetylator phenotype. N Engl J Med 1973;289:491-495.

6 Haagen Nielsen O, Bondesen S: Kinetics of 5-aminosalicylic acid after jejuna instillation in man. Br J Clin Pharmacol 1983;16:738-740.

7 Schroeder KW, Tremainen WJ, Ilstrup DM: Coated oral 5-aminosalicylic acid therapy for mildly to moderately active ulcerative colitis. A randomized study. N Engl J Med 1987;317:1625-1629.

8 Hanauer SB, Sninsky CA, Robinson M, et al: An oral preparation of mesalamine as long-term maintenance therapy for ulcerative colitis. A randomized, placebo-controlled trial. The Mesalamine Study Group. Ann Intern Med 1993;118:540-549.

-9 Hanauer SB, Schwartz J, Robinson M, et al: Mesalamine capsules for treatment of active ulcerative colitis. Results of a controlled trial. Am J Gastroenterol 1993;88:1188-1197.

10 Miner P, Hanauer SB, Robinson M, et al: Safety and efficacy of controlled-release mesalamine for maintenance of remission in ulcerative colitis. Dig Dis Sci 1995;40:296-304.

11 Marteau P, Nelet F, Lelu M, et al: Adverse events in patients treated with 5-aminosalicylic acid: 1993-1994 pharmacovigilance report for Pentasa in France. Aliment Pharmacol Ther 1996;10:949-956.

12 Fiorentini MT, Fracchia M, Galatola G, et al: Acute pancreatitis during oral 5-aminosalicylic acid therapy. Dig Dis Sci 1990;35:1180-1182. 
13 Scheurlen C, Allgayer H, Kruis W, et al: Effect of olsalazine and mesalazine on human ileal and colonic $\left(\mathrm{Na}^{+}+\mathrm{K}^{+}\right)$-ATPase. A possible diarrhogenic factor? Clin Investig 1993;71:286-289.

14 Goldstein F, DiMarino AJ: Diarrhea as a side effect of mesalamine treatment for inflammatory bowel disease. J Clin Gastroenterol 2000;31:60-62.

15 Kapur KC, Williams GT, Allison MC, et al: Mesalazine induced exacerbation of ulcerative colitis. Gut $1995 ; 37: 838-839$. 